\title{
Early Catheter Removal following Transurethral Prostatectomy: A Study of 431 Patients
}

\author{
Tatsuo Nakagawa ${ }^{a}$ Allan G. Toguri ${ }^{b}$ \\ ${ }^{a}$ Department of Urology, Nagano Matsushiro General Hospital, Nagano, Japan; ${ }^{b}$ Scarborough Hospital, \\ Toronto, Canada
}

\section{Key Words}

Transurethral resection of prostate $\cdot$ Catheterization, urinary

\begin{abstract}
Objectives: To assess and review catheter removal on the first day after transurethral prostatectomy. Subjects and Methods: The study included 431 consecutive patients who underwent transurethral prostatectomy between 2000 and 2003 at a Scarborough General Hospital, Toronto, Canada. The equipment used was a standard resectoscope with a regular loop. No roller ball or other gadget was used. The cutting and coagulation electrical variables were standard at 160 and $60 \mathrm{~W}$ for the generator used. The decision to remove the catheters was based on normal vital signs, adequate urine output, absence of clots and acceptable color of the catheter effluent. Results: Catheters were removed in $415(96.3 \%)$ patients on postoperative day 1 . Of the 415 patients $332(80.0 \%)$ were discharged on the same day. The criteria for catheter removal on postoperative day 1 were not met in $16(3.7 \%)$ patients and the mean indwelling catheter time was 4.8 \pm 2.4 days and the mean length of hospital stay after surgery was $6.2 \pm 3.3$ days. For the entire group, the mean indwelling catheter time was $1.1 \pm 0.8$ days and the mean
\end{abstract}

length of hospital stay after surgery was $1.6 \pm 1.5$ days. Risk factors which predicted delayed removal were age, postoperative bleeding and several comorbidities, that is coronary heart disease, renal insufficiency and Alzheimer's disease. Conclusions: Removal of the catheter on the first postoperative day after transurethral prostatectomy seems to be feasible, safe and cost-effective without increasing significant morbidity in selected patients.

Copyright (C) 2006 S. Karger AG, Basel

\section{Introduction}

Lengthy hospital stays have been considered to be a cost disadvantage of transurethral resection of prostate (TURP) when compared with newer treatments [1]. This disadvantage can be overcome by shortening the duration of postoperative catheterization. Until recently, catheters remained indwelling for 3-5 days postoperatively [2]. Currently, several practices of early catheter removal are used. Catheter removal on postoperative day 2, on postoperative day 1 and day-case prostatectomy can be accomplished in select patients if certain requirements can be satisfied [3-5]. From this study, the outcome, feasibility and safety of 431 consecutive patients for early catheter removal after TURP were examined.

\section{KARGER}

Fax +4161306 1234 E-Mail karger@karger.ch www.karger.com 


\section{Subjects and Methods}

A review was done of 431 consecutive patients (mean age 72.0 \pm 7.4 years) who underwent transurethral prostatectomy at a community hospital, Scarborough General Hospital, Toronto, Canada, from January 2000 through December 2003. Of these patients 60 had been previously diagnosed as adenocarcinoma of the prostate. This retrospective study was done on sequential patients. No patient was omitted or excluded from the analysis if they had a TURP. In the patients who were on anticoagulants, the drugs were stopped 4 days before surgery and also for 4 days after operation. The patients were of diverse ethnic groups and as a consequence it was not possible to assess symptom scores reliably. Flow rate patterns were used to some degree but in general, overall quality of life statements and failure of medical therapy were used to decide to offer TURP to the patients. Standard transurethral resection was performed with a tungsten cutting loop using a cutting current of $160 \mathrm{~W}$ and a coagulating current of $60 \mathrm{~W}$. The generator was Valleylab Force 4. No roller ball or other gadget was used. All operations were performed by a senior urologist (AGT) under spinal or general anesthesia. As a rule, the patients were hospitalized on the day of surgery. Postoperatively, catheter irrigation without traction was applied to all patients. The patients had glycine irrigation during and in transit to the recovery room. The irrigant was then changed to normal saline. The irrigation was run as long as necessary to maintain a less than red coloration to the irrigant.

Criteria for catheter removal included normal vital signs, absence of clots and acceptable character of the catheter effluent. The urine output was not measured. If there was a concern, a creatinine or blood urea nitrogen evaluation was done. If these criteria were met the next day after surgery, the catheter was removed. Patients who voided satisfactorily were discharged later that day.

Factors such as patient age, grams of resected tissue, the length of postoperative stay, recatheterization for the inability to void or bleeding, hospital discharge with a catheter, reoperation, comorbid conditions and postoperative complications were tabulated for patients whose catheter was removed 1 or more days postoperatively. The four preoperative comorbid conditions listed during the chart review were coronary artery disease, renal insufficiency (creatinine greater than $1.6 \mathrm{mg} / \mathrm{dl}$ ), diabetes mellitus and Alzheimer's disease. The three early postoperative complications listed were urinary tract infection, myocardial infarction and pneumonia. The three late postoperative complications listed were bladder neck contracture, urethral stricture and urinary bleeding. The patients were divided into two groups: early catheter removal (postoperative day 1) and late catheter removal (after postoperative day 1). Age, weight of resected tissue and the duration of hospital stay after surgery were compared using unpaired Student's $t$ test. The $\chi^{2}$ test or Fisher's exact test was used to compare the comorbidities and the complications.

\section{Results}

The outcome was considered successful in 415 patients (96.3\%), as the catheter was removed on the next day after operation. Of these patients $80 \%$ went home the same day of the catheter removal. Though 63 patients voided satisfactorily on postoperative day 1,48 patients were discharged the following day and 15 patients on day 3 . The absence of relatives to take care of the patient, distance of patient's home and anxiety after catheter removal were the main factors that had an influence on this decision. In $16(3.7 \%)$ patients the criteria for catheter removal on postoperative day 1 were not met. In these patients, catheters were removed $4.8 \pm 2.4$ days (mean \pm SD) after surgery. Mean patient age for early and late catheter removal was $71.8 \pm 7.3$ and $76.7 \pm 8$ years, respectively. The patients in the early removal group were significantly younger compared to the late removal group $(p<0.01)$. The weight of resected tissue was not significantly different between the two groups $(15.5 \pm 11.0 \mathrm{vs}$. $18.9 \pm 15.0 \mathrm{~g}, \mathrm{p}=0.230$ ). Mean length of stay after surgery was $1.4 \pm 1.0$ days for the early removal group and $6.2 \pm 3.3$ days for the late removal group. The length of hospital stay was significantly less in the early removal group compared to the late removal group $(\mathrm{p}<0.001)$. Postoperatively $7(43.8 \%)$ patients in the late removal group required recatheterization for bleeding, which was a significantly higher rate compared to the early removal group $(2.2 \%, p<0.001)$. However, the incidence of postoperative urinary retention (1.7 vs. $6.3 \%)$, discharge with an indwelling catheter (1.0 vs. $6.3 \%)$ and reoperation for bleeding $(0.7$ vs. $6.3 \%)$ was not statistically different between the groups (table 1).

Among 5 patients who were discharged with an indwelling catheter, 1 voided successfully after the catheter was removed. The remaining 4 patients required urethral catheter drainage secondary to hypocontractile bladder.

The most common preoperative comorbidity was hypertension in $43 \%$ of the whole patient group, gastrointestinal in $15.6 \%$ and arrhythmia in $14.1 \%$. The rates of the three comorbidities were not significantly different between the groups. The rate of preoperative coronary artery disease ( 7.5 vs. $25.0 \%$ ), renal insufficiency ( 2.4 vs. $18.8 \%)$ and Alzheimer's disease (0.5 vs. $12.5 \%)$ was significantly higher in the late removal group. As for the rate of diabetes mellitus, there was no significant difference between the groups $(10.4$ vs. $18.8 \%, p=0.513)$. The postoperative common complications were urinary tract infection, myocardial infarction and pneumonia. These three complications were evaluated specifically. The rate of urinary tract infection was not significantly different between the groups ( 1.2 vs. $6.3 \%, p=0.547)$. Only in the late removal group, 2 patients $(12.5 \%)$ had myocardial infarction and 2 patients (12.5\%) had pneumonia. Of the 2 patients who had myocardial infarction postoperatively, 1 was discharged on postoperative day 10 and the other on day 15 . Of the 2 patients who had pneumonia, 
Table 1. Demographics and inpatient events for 431 consecutive patients undergoing transurethral prostatectomy

\begin{tabular}{|c|c|c|c|}
\hline & \multicolumn{2}{|l|}{ Catheter out } & \multirow[t]{2}{*}{$\mathrm{p}$ value } \\
\hline & $\begin{array}{l}\text { on postoperative } \\
\text { day } 1\end{array}$ & $\begin{array}{l}\text { after postoperative } \\
\text { day } 1\end{array}$ & \\
\hline Catheter removal $^{\mathrm{a}}$ & $415(96.3)$ & $16(3.7)$ & \\
\hline \multicolumn{4}{|l|}{ Age, years } \\
\hline Mean $\pm \mathrm{SD}^{\mathrm{b}}$ & $71.8 \pm 7.3(50-93)$ & $76.7 \pm 8.0(65-90)$ & $<0.01^{\mathrm{c}}$ \\
\hline Median & 72 & 75 & \\
\hline \multicolumn{4}{|l|}{ Weight of resected tissue, $\mathrm{g}$} \\
\hline Mean $\pm \mathrm{SD}^{\mathrm{b}}$ & $15.5 \pm 11.0(1-68)$ & $18.9 \pm 15.0(3-60)$ & 0.230 \\
\hline Median & 12 & 15 & \\
\hline \multicolumn{4}{|l|}{ Hospital stay after surgery, days } \\
\hline Mean \pm SD $^{\mathrm{b}}$ & $1.4 \pm 1.0(1-10)$ & $6.2 \pm 3.3(2-15)$ & $<0.001^{\mathrm{c}}$ \\
\hline Median & 1 & 6 & \\
\hline $\begin{array}{l}\text { Urinary retention requiring } \\
\text { recatheterization }{ }^{\mathrm{a}}\end{array}$ & $7(1.7)$ & $1(6.3)$ & $0.702^{\mathrm{d}}$ \\
\hline Discharged with catheter $^{\mathrm{a}}$ & $4(1.0)$ & $1(6.3)$ & $0.454^{\mathrm{d}}$ \\
\hline Bleeding requiring recatheterization ${ }^{a}$ & $9(2.2)$ & $7(43.8)$ & $<0.001^{\mathrm{e}}$ \\
\hline Return to surgery ${ }^{\mathrm{a}}$ & $3(0.7)$ & $1(6.3)$ & $0.350^{\mathrm{d}}$ \\
\hline $\begin{array}{l}\text { a Figures in parentheses represent } \\
{ }^{b} \text { Figures in parentheses represent } \\
{ }^{\mathrm{c}} \text { Unpaired Student's t test. } \\
{ }^{\mathrm{d}} \text { Fisher's exact test. } \\
{ }^{\mathrm{e}} \text { Yates } \chi^{2} \text { test. }\end{array}$ & $\begin{array}{l}\text { percentage. } \\
\text { range. }\end{array}$ & & \\
\hline
\end{tabular}

1 was discharged on postoperative day 8 and the other on day 9 . There were no perioperative deaths in this study (table 2). In terms of late complications, in the early removal group, 9 patients $(2.2 \%)$ had bladder neck contracture requiring urethrotomy, 9 patients $(2.2 \%)$ had urethral stricture requiring dilation and 7 patients $(1.7 \%)$ required recatheterization due to bleeding (table 2).

Thirteen patients required perioperative blood transfusion $(3.0 \%)$. All of these patients had anemia before operation and the mean hemoglobin of these patients before operation was $10.1 \pm 1.3 \mathrm{mg} / \mathrm{dl}$ (range 7.9-12.4). The rate of blood transfusion was significantly lower in the early removal group compared to the late removal group ( 1.9 vs. $31.3 \%, \mathrm{p}<0.001)$.

Adenocarcinoma was identified in 29 patients (7.8\%) who were diagnosed as benign prostatic hyperplasia before transurethral resection.

\section{Discussion}

The duration of postoperative hospitalization and indwelling urethral catheterization has been significantly reduced during the last decade [3-5]. Studies reported that early catheter removal has reduced the length of hospital stay, which in turn would be beneficial to health care costs $[1,6]$. In addition to cost savings, early catheter removal and early discharge thereafter may bring advantages especially for patients for whom an early return to their employment is required. Short-term urinary catheterization can also reduce the risk of urinary tract infections associated with an indwelling catheter [7].

In the Cherrie et al. [1] study of 200 patients $78 \%$ were catheter-free on postoperative day 1 and $80 \%$ of them were discharged without a catheter on the same day. In another study by Aslan et al. [3] 54 (79.6\%) patients were catheter-free on postoperative day 1 and $52 \%$ of those were discharged home on the same day. In our study, $96.3 \%$ were catheter-free on postoperative day 1 and $80 \%$ of them were discharged on the same day. The difference in catheter-free patients on postoperative day 1 between our study and those of Cherrie et al. [1] and Aslan et al. [3] is significant $(p<0.001)$. This difference may be secondary to improvements in anesthesia and operative technique that include maintaining meticulous hemostasis during operation and point coagulation of arterial bleeders. 
Table 2. Preoperative comorbidities, early postoperative complications and late postoperative complications

\begin{tabular}{|c|c|c|c|}
\hline & \multicolumn{2}{|l|}{ Catheter out } & \multirow[t]{2}{*}{$\mathrm{p}$ value } \\
\hline & $\begin{array}{l}\text { on postoperative } \\
\text { day } 1\end{array}$ & $\begin{array}{l}\text { after postoperative } \\
\text { day } 1\end{array}$ & \\
\hline \multicolumn{4}{|l|}{ Comorbidities } \\
\hline Coronary artery disease & $31(7.5)$ & $4(25.0)$ & $0.040^{\mathrm{a}}$ \\
\hline Renal insufficiency & $10(2.4)$ & $3(18.8)$ & $0.003^{\mathrm{b}}$ \\
\hline Diabetes mellitus & $43(10.4)$ & $3(18.8)$ & $0.513^{\mathrm{b}}$ \\
\hline Alzheimer's disease & $2(0.5)$ & $2(12.5)$ & $<0.001^{\mathrm{b}}$ \\
\hline \multicolumn{4}{|l|}{ Early postoperative complications } \\
\hline Urinary tract infection & $5(1.2)$ & $1(6.3)$ & $0.547^{\mathrm{b}}$ \\
\hline Myocardial infarction & $0(0)$ & $2(12.5)$ & \\
\hline Pneumonia & $0(0)$ & $2(12.5)$ & \\
\hline \multicolumn{4}{|l|}{ Late postoperative complications } \\
\hline Bladder neck contracture & $9(2.2)$ & $0(0)$ & \\
\hline Urethral stricture & $9(2.2)$ & $0(0)$ & \\
\hline Late postoperative bleeding & $7(1.7)$ & $0(0)$ & \\
\hline
\end{tabular}

Figures in parentheses represent percentage.

a Yates $\chi^{2}$ test.

${ }^{\mathrm{b}}$ Fisher's exact test.

Table 3. Late postoperative complications

\begin{tabular}{llll}
\hline Complications & $\begin{array}{l}\text { Our study } \\
(\mathrm{n}=431)\end{array}$ & $\begin{array}{l}\text { Borboroglu et al. } \\
{[8](\mathrm{n}=520)}\end{array}$ & p value \\
\hline Bladder neck contracture & $9(2.2)$ & $11(2.1)$ & $0.843^{\mathrm{a}}$ \\
Urethral stricture & $9(2.2)$ & $5(1.0)$ & $0.244^{\mathrm{a}}$ \\
Late postoperative bleeding & $7(1.7)$ & $7(1.3)$ & $0.933^{\mathrm{a}}$ \\
\hline
\end{tabular}

Figures in parentheses represent percentage.

${ }^{a} \chi^{2}$ test.

The mean hospital stay after operation of $1.6 \pm 1.5$ days for the entire patient population of our study is similar to other reports $[1,3,8]$. The length of catheterization correlated with age, postoperative bleeding and several comorbidities which were coronary heart disease, renal insufficiency and Alzheimer's disease.

The incidence of postoperative urinary retention, discharge with indwelling catheter and reoperation was not significantly higher in the early than late catheter removal group. However it is possible that if the study group had been larger, the $\mathrm{p}$ values could be significant. The size of the prostate gland removed was not a criterion for longer catheterization as previously reported [1].

The duration of catheterization ( $1.1 \pm 0.8$ days $)$ of this study was shorter than that reported by Borboroglu et al.
[8] of 3.2 days. Although the length of catheterization in our patients was shorter, however, there was no significant difference for the incidence of bladder neck contracture, urethral stricture and bleeding after hospital discharge (table 3) [8].

Our 3.0\% rate of perioperative blood transfusion was lower than that reported by Mebust et al. [2] (2.5\% intraoperatively and $3.7 \%$ postoperatively) but higher than that reported by Borboroglu et al. [8] (0.4\%). In our cases, all patients who had blood transfusion were anemic prior to operation and had several comorbidities that included coronary heart disease and renal insufficiency. Hence we postulate that not only surgery but also the state of anemia before operation was the cause of blood transfusion. 
Of the new treatment modalities for benign prostatic hyperplasia, laser techniques are one of the most promising. Since laser techniques are less invasive and faster, they can often be performed on an outpatient basis. Laser techniques are not available in many medical centers, and equally important their long-term effects are not known [9]. Hence it was not possible to compare laser techniques of prostatic resection techniques with the current gold standard of TURP which is effective and efficient in patient management.

\section{Conclusions}

Our data indicate that early catheter removal on postoperative day 1 is safe for the majority of patients without increased complications. Risk factors which predicted delayed removal were age, postoperative bleeding and several comorbidities (coronary heart disease, renal insufficiency and Alzheimer's disease). Early catheter removal is cost-effective and improves the quality of life for patients.

\section{References}

1 Cherrie RJ, Young RA, Cattolica EV: The safety of overnight hospitalization for transurethral prostatectomy: a prospective study of 200 patients. J Urol 1997;157:531-533.

-2 Mebust WK, Holtgrewe HL, Cockett ATK, Peters PC: Transurethral prostatectomy: immediate and postoperative complications. A cooperative study of 143 participating institutions evaluating 3,885 patients. J Urol $1989 ; 141$ : 243-247.
-3 Aslan G, Celebi I, Arslan D, Esen AA: Early catheter removal following transurethral prostatectomy: overnight catheterization. Urol Int 2002;68:105-108.

-4 Chander J, Vanitha V, Lal P, Ramteke VK Transurethral resection of the prostate as catheter-free day-care surgery. BJU Int 2003;92: 422-425.

$>5$ Gordon NSI: Catheter-free same day surgery transurethral resection of the prostate. J Urol 1998;160:1709-1712.

-6 Mueller EJ, Zeidmann EJ, Desmond PM, Thompson IM, Optenberg SA, Wasson J: Reduction of length of stay and cost of transurethral resection of the prostate by early catheter removal. Br J Urol 1996;78:893-896.
7 Kunin CM, McCormack RC: Prevention of catheter-induced urinary-tract infections by sterile closed drainage. N Engl J Med 1966; 274:1156-1161.

${ }_{8}$ Borboroglu PG, Kane CJ, Ward JF, Roberts JL, Sands JP: Immediate and postoperative complications of transurethral prostatectomy in the 1990s. J Urol 1999; 162:1307-1310.

-9 McNicholas TA, Singh S: The use of lasers in benign prostatic enlargement. Curr Urol Rep 2000;1:124-131. 